\title{
An assessment tool to help producers improve cow comfort on their farms
}

\author{
E. Vasseur, ${ }^{* 1,2}$ J. Gibbons, ${ }^{*}$ J. Rushen, ${ }^{*}$ D. Pellerin,† E. Pajor,‡ D. Lefebvre,§ and A. M. de Passillé ${ }^{*}$ \\ ${ }^{*}$ Pacific Agri-Food Research Centre, Agriculture and Agri-Food Canada, Agassiz, British Columbia, Canada, V0M 1A0 \\ †Animal Science Department, Université Laval, Quebec, Quebec, Canada, G1K 7P4 \\ ‡Department of Production Animal Health, University of Calgary, Calgary, Alberta, Canada, T2N 1N4 \\ §Valacta Inc., Dairy Production Centre of Expertise Quebec-Atlantics, Sainte-Anne-de-Bellevue, Quebec, Canada, H9X 3R4
}

\begin{abstract}
Effective management and an appropriate environment are essential for dairy cattle health and welfare. Codes of practice provide dairy producers with best practice guidance for the care and handling of their cattle. New Canadian recommendations have been established for the dairy industry. The objectives of this study were to develop an on-farm assessment tool that helps producers assess how well they are meeting their code of practice and that identifies management and environment modifications that could improve dairy cow comfort on their farms. The assessment tool addressed critical areas of dairy cow comfort, including accommodation and housing (stall design, space allowance, stall management, pen management, milking parlor, and transfer alleys), feed and water (body condition scoring, nutrition), and health and welfare (lameness, claw health, and hoof-trimming). Targets of good practices were identified from the requirements and recommendations of the code of practice. Each farm received a score for each target, ranging from 0 (target not reached) to 100 (target reached). One hundred tiestall and 110 freestall farms were surveyed in 3 provinces of Canada (Quebec, Ontario, and Alberta). The duration of the assessment, in 2 visits lasting, on average, 8 and $9 \mathrm{~h}$ (range between freestall and tiestall farms) and 4 and $4.1 \mathrm{~h}$, was beyond the targeted 3 to $4 \mathrm{~h}$ due mainly to the animal-based measures; strategies to reduce the duration of the assessment were discussed. Standard operating procedures were developed to ensure consistency in measuring and recording data. Periodical checks were conducted by trainers to ensure all 15 assessors remained above target agreement of weighted kappa $\geq 0.6$. Average scores for all critical areas ranged from 25 to $89 \%$ for freestall farms and from 48 to $95 \%$ for tiestall farms. These scores need to be considered with caution when comparing farms because
\end{abstract}

\footnotetext{
Received April 10, 2014.

Accepted September 20, 2014.

${ }^{1}$ Corresponding author: vasseur.elsa@gmail.com

${ }^{2}$ Current address: Organic Dairy Research Center, University of Guelph, Alfred, Ontario, Canada, K0B 1A0.
}

scores could not always be calculated the same way between housing systems. An evaluation report was provided and discussed with each producer, identifying strengths and areas for improvement that could benefit dairy cow comfort on their farms. The producers were convinced of the effectiveness of our tool for assessing cow comfort (freestall: 86\%; tiestall: 95\%) and in assisting them to make decisions for improvements (freestall: 83\%; tiestall: 93\%). Our cow comfort assessment tool served as background material for the Dairy Farmers of Canada animal care assessment program.

Key words: assessment tool, dairy cow comfort, freestall, tiestall

\section{INTRODUCTION}

Dairy producers are required to meet an increasing number of animal welfare standards (Rushen et al., 2011). Although many standards are developed by food retailers (Mench, 2008), producer groups are developing their own standards as a means of ensuring consumer confidence. For example, in Canada, new guidelines have been established for the care and handling of dairy cattle by the Dairy Farmers of Canada (DFC) and the National Farm Animal Care Council (DFC-NFACC, 2009), which include recommended best practices and requirements. The next logical step following the implementation of codes of practice is the development of robust animal welfare assessment programs that accurately reflect the welfare status of animals. Such assessment programs often have 2 goals. The first is to provide a means of assurance to consumers that food is from animals that have been raised humanely. The second goal is as an assessment tool that allows producers to self-assess their management practices and provides them with the information needed to improve animal welfare on their farms (Vasseur et al., 2010).

As a natural extension of the DFC Code of Practice implementation, the objective of this research project was to develop an on-farm animal comfort assessment tool that helps producers assess how well they are meeting the Code (DFC-NFACC, 2009) and that identifies management and environment modifications that could 
improve dairy cow comfort on their farms. In our assessment of the tool, we considered both the feasibility of using it on farms and the likelihood that it would be implemented by field advisors and producers. Five goals were established that would need to be met if the tool were to be implemented successfully. The time required to complete an animal welfare assessment is a critical factor in its success (Sørensen et al., 2007). Our first goal was to ensure that the evaluation could be completed within an acceptable time limit. The second goal was that data should be collected in the same way by multiple, independent assessors, to ensure a highly repeatable assessment. The third goal was to check that the targets set for the farm evaluation are realistic in terms of their ability to discriminate between herds and at the same time, ensure that areas of improvement are detectable. Finally, the fourth goal was to ensure that the dairy producers, who are the end users of the assessment tool, would consider this tool useful in encouraging improvements in dairy cattle comfort.

\section{MATERIALS AND METHODS}

\section{Development of the Tool}

Our methodology was based on a previous project that developed an assessment tool to improve management practices affecting calf and heifer welfare on dairy farms (Vasseur et al., 2010). For the present project, an assessment tool was developed for dairy producers to assess how well they are meeting their Code of Practice (DFC-NFACC , 2009) and to identify management and environment modifications to improve dairy cow comfort on their farms.

Identifying Critical Areas and Determination of Targets. First, critical areas of dairy cow comfort were identified (Table 1) for both freestall (13 critical areas) and tiestall (9 critical areas) farms based on areas of dairy cow comfort covered by the Code of Practice for the care and handling of dairy cattle (DFC-NFACC, 2009). Quantifiable targets were developed that producers should reach to demonstrate best practices in each critical area (Table 1). Thirty-two targets were identified based on the requirements and recommended best practices of the Code of Practice, which were derived from the most current evidence in the scientific literature (Rushen et al., 2009). Some requirements or recommended practices of the Code of Practice were clearly quantified; for example, "aim for prevalence of $<10 \%$ for severe lameness," whereas others were replaced by quantifiable targets; for example, "cattle must have a bed that provides comfort, insulation, warmth, dryness and traction" was replaced by "provide deep-bedded dry stalls" (Table 1). In some cases, the targets were complemented by additional scientific information where this was judged appropriate. For example, a requirement of the Code of Practice is to "build stalls to minimize hock and knee injuries (...)." However, some aspects of stall configuration have been associated with neck injuries; for example, higher tierails may decrease risks for neck injuries in tiestalls (Zurbrigg et al., 2005b), and reported prevalence of neck injuries ranged from 4 to $22 \%$ of the cows (Zurbrigg et al., 2005a; Kielland et al., 2009). Therefore, it was judged appropriate to complement the requirement of the Code of Practice by measuring neck injuries as well as hock and knee injuries, and a target was defined (Table 1) as "comfortable stalls minimize hock, knee, and neck injuries" for the critical area "hock, knee and neck injuries."

Defining Indicators. Once targets were established, indicators were defined (Table 1) as a combination of one or more measures that could be used to assess the extent to which the targets were being met. These indicators were based on measures that could be reliably recorded by trained assessors. These included animal-based measures that were taken directly from focal cows (Table 1); environment-based measures that were based on observations made during the visits to the housing facilities, milking parlor, holding pens, and transfer alleys; and management-based measures that were developed from producers' answers during an interview.

Animal-Based Measures. Standard operating procedures (SOP) were developed and tested for each animal based-measure (e.g., injuries; Gibbons et al., 2011). The SOPs are available on the Canadian Dairy Research Portal (https://www.dairyresearch.ca/cowcomfort.php\#self). The SOPs include information on the various locations of the dairy barn in which the measures could best be taken; for example, BCS is best evaluated while cows are headlocked at the feedbunk (Vasseur et al., 2013). The SOPs detailed the procedure and provided a step-by-step instruction that enabled assessors to evaluate the measures in a consistent manner. Measures taken on cows were reported either as herd average (e.g., herd daily duration of lying time was calculated based on overall averages over $4 \mathrm{~d}$ ) or prevalence (e.g., herd prevalence of neck injuries on the day of the visit).

Environment-Based Measures. Two types of measures of the cow's environment were recorded. The first type of measure was quantitative. For example, stall dimensions (Table 1) were measured using a preestablished SOP. The assessor selected 3 rows of stalls representing each stall type (e.g., head-to-head and head-to-wall). The first and last usable stalls of each row were measured for all 8 dimensions (Table 2), and the middle 2 stalls of each row were measured for stall 
Table 1. Critical areas, targets (and references to sections of Code of Practices, DFC-NFACC, 2009), and descriptions of indicators for measures taken on focal cows (animal-based measures), by the assessors during the visits to the barn (environment-based) and during an interview with the producer (management-based)

\begin{tabular}{l} 
Critical area \\
\hline Lying time \\
Hock, knee and \\
neck injuries \\
Stall configuration
\end{tabular}

Target

Comfortable dairy cows lie down for

$12 \mathrm{~h} / \mathrm{d}$

Comfortable stalls minimize hock,

knee and neck injuries

The average stalls meet

recommendations for the "heaviest

$0 \%$ " cow for each of the 9

dimensions

$100 \%$ of cows fitting in the average stall for bed length and width ${ }^{2}$

The average multiparous Holstein

Canadian cow fits in the average stall for bed length and width ${ }^{3}$

Space allowance at $\quad$ Stocking density must not exceed 1.2 the stalls ${ }^{4}$ Space allowance at Linear feed bunk space must be

at least $60 \mathrm{~cm} / \mathrm{cow}$ to reduce

competition

Limit competition at the feed bunk

Limit competition at the feed bun
by the presence of a barrier at feed by the
bunk

The alley where cows stand to feed should be at least $4.3 \mathrm{~m}$ to allow sufficient space for feeding and animal displacement

Height of feed barrier must be high enough to allow all cows to feed

comfortably (no risk of neck injuries) type and quality

Provide deep-bedded dry stalls

Stall/bedding management

Pen management (standing areas)

Cows must be kept in an environment with a low level of contamination (evaluation of cow cleanliness)

Cows must be kept in an environment with a low level of contamination (evaluation of stall cleanliness) Stalls must be cleaned at every milking

Stalls must be routinely bedded (more than once a week)

Minimize the time cows spend standing on concrete in the pen Provide slip-resistant flooring in standing areas of the pen
Indicator

Herd average lying time calculated from accelerometers on 40 focal cows $\times 4 \mathrm{~d}$

Percentage of (40 focal) cows without injuries for hock, knee and neck

Average measure (of first and last usable stalls of each row per pen, and an additional 2 stalls in the middle of each row for stall width; min. of 6 stalls/farm) for stall width, stall length, bed length, brisket board height, height of upper edge of bottom divide rail above stall surface, lunge space, neck rail height, distance of neck rail from rear curb of stall, curb height Body dimensions evaluated from a min. of 10 heaviest cows measured for rump height and hook bone width

1.4 Percentage of cows ( $\mathrm{n}=$ cows evaluated for body dimensions) fitting in the average stall for bed length and width

1.4 The average multiparous Holstein Canadian cow ( $\mathrm{BW}=727$ The average multiparous Holstein Canadian cow $(\mathrm{BW}=727$
$\mathrm{kg}$ ) fits or does not fit in the average stall for bed length and width

1.5; $3.6 \quad$ Number of cows in pen divided per number of usable stalls

Animal Environment Management

(no.)

(no.)

$1.5 ; 1.7 ; \quad$ Length of all feeders in pen divided per number of cows

Presence of headlocks or partitions between cows

1.5 Width of the alley where cows stand to feed

Height of feed barrier compared with $85 \%$ of rump height of the $10 \%$ highest cows $(\mathrm{n}=$ cows evaluated for body dimensions)

$1.6 ; 3.6$ 3.10

$1.6 ; 3.6$

1.6. 3.6 ; $3.10 ; 4.6$

Type of bedding

Estimation of bedding quantity level $(\mathrm{n}=\min .6$ stalls/farm same sample stalls measured for stall design)

Estimation of bedding dryness level $(\mathrm{n}=\min .6$ stalls/farm;

same sample stalls measured for stall design)

Percentage of (40 focal) cows clean or with light contamination on upper leg-flank, udder, and lower leg

Estimation of stall cleanliness level $(\mathrm{n}=$ min. 6 stalls/farm; same sample stalls measured for stall design)

Frequency of raking and cow patty remova

Frequency of new bedding adding

Type of flooring in standing areas

4.1 Percentage of cows slipping or falling while encouraged to walk to the milking parlor 
Table 1 (Continued). Critical areas, targets (and references to sections of Code of Practices, DFC-NFACC, 2009), and descriptions of indicators for measures taken on focal cows (animal-based measures), by the assessors during the visits to the barn (environment-based) and during an interview with the producer (management-based)

\begin{tabular}{|c|c|c|c|c|c|c|}
\hline Critical area & Target & Section & Indicator & $\begin{array}{c}\text { Animal } \\
(\text { no. })\end{array}$ & $\begin{array}{l}\text { Environment } \\
\quad(\text { no. })\end{array}$ & $\begin{array}{l}\text { Management } \\
\text { (no.) }\end{array}$ \\
\hline \multirow{5}{*}{$\begin{array}{l}\text { Milking parlor, } \\
\text { holding pens and } \\
\text { transfer alleys } \\
\text { management }^{1}\end{array}$} & $\begin{array}{l}\text { Ensure the floor is cleaned in } \\
\text { standing areas of the pen }\end{array}$ & $\begin{array}{l}3.5 ; 3.10 \\
4.6\end{array}$ & $\begin{array}{l}\text { Estimation of stall floor cleanliness level (estimated } 2 \text { times: } 20 \\
\text { min before and after scraping/flushing) }\end{array}$ & & 1 & \\
\hline & $\begin{array}{l}\text { Flush and/or scrape } 2-3 \text { times per } \\
\text { day in standing areas of the pen }\end{array}$ & $3.5 ; 3.10$ & Frequency of flushing/scraping standing areas & & & 1 \\
\hline & $\begin{array}{l}\text { Minimize milking and holding time } \\
\text { below } 2 \mathrm{~h} \text { per day }\end{array}$ & $1.8 ; 4.8$ & $\begin{array}{l}\text { Estimation of the time between when the first cow of the group } \\
\text { is taken out of the home pen for milking and the last cow of the } \\
\text { group is back in the home pen }\end{array}$ & & 1 & \\
\hline & $\begin{array}{l}\text { Minimize the time cows spend in } \\
\text { concrete in the milking parlor, } \\
\text { holding area and alleys to the milking } \\
\text { parlor }\end{array}$ & $\begin{array}{l}1.8 ; 1.9 \\
3.5 ; 4.8\end{array}$ & $\begin{array}{l}\text { Type of flooring in milking parlor, holding area and alleys to } \\
\text { the milking parlor }\end{array}$ & & 3 & \\
\hline & $\begin{array}{l}\text { Flush and/or scrape } 2-3 \text { times per } \\
\text { day in alleys to the milking parlor }\end{array}$ & $1.9 ; 3.10$ & Frequency of flushing/scraping the transfer alleys & & & 1 \\
\hline \multirow{4}{*}{$\begin{array}{l}\text { Body condition } \\
\text { scoring } \\
\text { Nutrition } \\
\text { and feeding } \\
\text { management }\end{array}$} & $\begin{array}{l}\text { No cows should be at a BCS of } 2 \text { or } \\
\text { lower (poor BCS) }\end{array}$ & 2.1 & Percentage of (40 focal) cows with BCS $\leq 2$ (poor BCS) & 1 & & \\
\hline & Provide feed to the cow daily & 2.2 & Frequency of feed delivery & & & 1 \\
\hline & Keep a consistent feeding schedule & 2.2 & Consistent feed delivery schedule & & & 1 \\
\hline & Ensure continuous access to feed & 2.2 & $\begin{array}{l}\text { Estimation of continuous feed access (estimated } 4 \text { times). } \\
\text { Multiple push-ups if TMR or multiple deliveries of forages and } \\
\text { concentrates if no TMR }\end{array}$ & & 4 & 1 \\
\hline \multirow[t]{4}{*}{ Lameness } & $\begin{array}{l}\text { Fewer than } 10 \% \text { obvious or severe } \\
\text { lame cows }\end{array}$ & 3.5 & Percentage of (40 focal) obviously/severely lame cows & 1 & & \\
\hline & $\begin{array}{l}\text { Routinely observe cows for lameness } \\
\text { (at least once a week) }\end{array}$ & $3.5 ; 3.9$ & Lameness monitoring routine schedule & & & 1 \\
\hline & Proper procedure to treat lame cows & 3.9 & Lameness treatment procedure & & & 1 \\
\hline & Keep complete records of lameness & & Lameness record keeping & & & 1 \\
\hline \multirow[t]{2}{*}{$\begin{array}{l}\text { Claw health/hoof- } \\
\text { trimming }\end{array}$} & $\begin{array}{l}\text { Trim claw approximately } 2 \text { mo before } \\
\text { calving to prevent and minimize } \\
\text { lameness after calving }\end{array}$ & 4.9 & Hoof-trimming routine schedule & & & 1 \\
\hline & $\begin{array}{l}\text { Keep complete records of hoof- } \\
\text { trimming }\end{array}$ & 4.9 & Hoof-trimming record keeping & & & 1 \\
\hline
\end{tabular}

${ }^{1}$ This target was replaced for tiestall farms by the following 2 targets: "100\% of cows fitting in their stall for electric trainer position" (Code of Practice section 3.14) (indicator: percentage of cows fitting in their stall for horizontal position and height of electric trainer; $\mathrm{n}=2$ environment-based measures evaluated on individual 40 focal cow-stalls) and " $100 \%$ $\infty$ of cows fitting in their stall for lunge space" (indicator: percentage of cows fitting in the average stall for lunge space; $\mathrm{n}=1$ environment-based measure evaluated on individual 40 . focal cow-stalls). Individual BW evaluated from 40 focal cows in tiestall measured for rump height and hook bone width ( $\mathrm{n}=1$ animal-based measure).

จ ${ }^{2}$ This target was replaced for tiestall farms by the following target: "100\% of cows fitting in their stall for bed length and width" (indicator: percentage of cows fitting in their stall $\delta \quad$ for bed length and width; $\mathrm{n}=2$ environment-based measures evaluated on individual 40 focal cow-stalls). Individual BW evaluated from 40 focal cows in tiestall measured for rump 을 $\quad$ height and hook bone width ( $\mathrm{n}=1$ animal-based measure).

$œ{ }^{3}$ This target was excluded for tiestall farms.

Z $\quad{ }^{4}$ This critical area was excluded for tiestall farms. 
width only. A minimum of 6 stalls had to be measured per farm. A diagram was provided to facilitate stall sampling with clearly defined definitions for each dimension (Table 2).

The second type of environment-based measure involved making qualitative estimates. For example, on the same sample of stalls, the assessor estimated the bedding quantity (Table 1) by measuring at 2 spots near the back of the stall after raking the bedding flat. The assessor chose for each stall on the following scale: $1=$ none, if unable to measure because there is so little bedding; $2=$ little, bedding $\leq 2 \mathrm{~cm}$ equivalent to $1 \mathrm{~kg}$ of straw; or $3=$ deep, bedding $>2 \mathrm{~cm}$ equivalent to 1 $\mathrm{kg}$ of straw.

Management-Based Measures. The questions during the interview on cow management with the producer were either qualitative nominal; for example, "Do you keep records of hoof-trimming?" (answer: yes or no) or qualitative ordinal; for example, "How often new bedding is added?" (scale of answer: $1=$ once a day to $5=$ less than once a week).

Tool Validation. Fifteen researchers and extension specialists of several fields related to dairy cow comfort (behavior, nutrition, health, management) participated in the design or conceptual validation of our tool (Bockstaller and Girardin, 2003) to judge the scientific quality of the construction of the tool. This consultation occurred over a 6 -mo period and was conducted over the phone and via e-mail exchanges. The expert group examined and discussed the critical areas, targets, indicators, and measures until the group reached consensus. All components of our tool were submitted for review (e.g., SOP for data collection, data recording sheets, evaluation report to producers) until the group reached consensus. All components of our tool are available free of charge on the internet (Canadian Dairy Research Portal; https://www.dairyresearch.ca/ animal-comfort-tool.php).

Assignment of Scores. All critical areas were assumed equally important for animal comfort and so were given equal weighting and assigned a maximum possible score of 100 (good level of comfort). Within each critical area, targets were considered equally important and, within each target, indicators were considered equally important. Therefore, to assign a maximum possible score for each target, the maximum score for each critical area (100) was divided by the number of targets. The same process was repeated to equally weight the indicators within each target.

\section{On-Farm Test of the Tool}

Our tool was tested during an epidemiological study on cow comfort conducted from 2010 to 2012. For that 
purpose, the primary goal of the research project was to take advantage of the opportunity to be on $210 \mathrm{com}-$ mercial farms when collecting numerous data on the animals, the environment, and management, and to investigate how they interrelate and are related to cow comfort (e.g., Zaffino Heyerhoff et al., 2014).

Farm and Animal Selections. One hundred tiestall and 110 freestall farms were surveyed in Quebec, Ontario, and Alberta. To be eligible for participation, farms had to be enrolled with a milking recording system (CanWest DHI in Ontario and Alberta; Valacta Inc. in Quebec), with average milk production $>7,000$ $\mathrm{kg} /$ cow per year, a herd size of more than 40 lactating cows, and Holstein cows. Producers were invited to participate in the study by mail and had to send a letter indicating their willingness to participate in Ontario and Alberta or were called by an advisor from Valacta Inc. in Quebec. They were then interviewed by phone to determine if they met the study criteria, which included having cows stall-housed in their present barn for at least $1 \mathrm{yr}$, and no access to outdoor exercise area or pasture. These criteria were chosen to ensure surveyed farms were representative of the housing situation on the majority of Canadian dairy farms. Farms were also selected on longevity, defined by both percentage of cows in third lactation and higher and replacement rate to capture, at the province level, high-, medium-, and low-longevity herds. In Alberta, all selected farms were enrolled in another project (The Alberta Hoof Health Project). Based on milking recording system values averaged over 3 yr (2008-2011), the size of surveyed farms was $160 \pm 94$ (minimum-maximum: 47-513) cows for freestall herds and $66 \pm 17$ (43-121) for tiestall herds, and milk production was 9,921 $\pm 978(7,321-12,160)$ $\mathrm{kg}$ of milk/cow per year for freestall and 9,570 \pm 875 $(7,511-11,870)$ for tiestall herds.

From each herd, 40 focal cows in early lactation (10-120 DIM) were selected for animal-based measures (e.g., lying time, injuries; Table 1). The sample size and cow selection criteria (i.e., stage of lactation) were chosen to ensure an accurate sample and allow for losses of observations for the measurement of lying time, as recommended by Vasseur et al. (2012). The rationale behind selecting focal cows in early lactation was that the cow is producing a lot of milk at that time and is most challenged by disease risk (Ingvartsen et al., 2003); therefore, cow welfare is most likely to be compromised.

Quality Control of Data. Two assessors per farm were responsible for data collection, and assessors varied by farms. The study included 15 assessors with varying degrees of experience working with dairy cattle, either graduate students or research assistants from collaborating universities. All assessors under- went an intensive 2 -wk training program by the same trainer and were trained on animal-, environment-, and management-based measures, as well as on handling the accelerometers used to measure lying time, data entry, and generating and discussing the evaluation report with the producer. One assessor per farm was responsible for each measure and task. Standard operating procedures were developed to ensure that all assessors took the measures the same way, and periodic checks were conducted by trainers to ensure all assessors remained highly repeatable during the data collection period (e.g., injuries; Gibbons et al., 2011).

Tool Practicality. Tool practicality refers to its ease of use and duration of the assessment, and it was tested based on the timing and ability of assessors to take the measures during 2 farm visits. Those visits were scheduled to install and remove accelerometers and collect measures of lying time over a minimum consecutive 4-d period (as defined in Vasseur et al., 2012) up to a maximum of $10 \mathrm{~d}$. To evaluate the time required to do the visit on each farm, times were recorded on the schedule for each farm visit where time required for each task was reported by each assessor individually and the 2 assessors simultaneously.

Ability of the Tool to Discriminate Between Farms. During visits to the farm, each farm was scored for each critical area and target based on animal-, environment-, and management-based measures. The discriminative ability of the tool was judged by analyzing the distribution and variability of the scores obtained on different farms. To ensure that our targets were realistic in terms of their ability to discriminate between herds, average farm scores would have to be around $50 \%$ for most of the targets. The rationale was that if most producers scored close to 100 for most of the targets, problem farms would be probably missed, whereas if most producers scored close to 0 , then our targets were unrealistic.

This scoring was discussed with the producer at the end of the on-farm visits. For each target, the recommendations of the Code of Practice (DFC-NFACC, 2009) were explained as well as the research that had been done, which supported our scoring. A report was provided to the producers, who could forward it to advisors or consultants. A complimentary copy of the Code of Practice was offered to producers.

Tool Usefulness as Judged by Producers. The final step of the on-farm visits was a debriefing interview to collect producers' perceptions of the suitability of the tool for the purpose for which it has been designed. Producer were asked their opinion about the ease of use of the tool, the time involved for the assessment, and whether this assessment could help them change housing conditions and management practices to im- 
prove cow comfort on their farms. Producers provided feedback on the usefulness of the overall assessment tool and scoring system (e.g., "how well does our tool cover the following aspects of cow comfort?"). Scales of perceptions (qualitative or ordinal data) and open questions (e.g., "provide examples of other aspects of cow comfort that should be covered in our tool") were included. Producers were given the opportunity to highlight any weaknesses regarding the indicators and components of the tool as a decision aid. Finally, producers were asked their views on being audited and accredited for cow comfort using part of this tool.

\section{Data Analysis}

Descriptive results of the timing of the farm visits were analyzed using a strength and weakness analysis to evaluate tool practicality. Tool usefulness was evaluated using descriptive statistics to analyze farms' scoring and answers to the debriefing interview. Freestall and tiestall scores were analyzed separately. Data were entered into Access (versions 2003 and 2007; Microsoft Corp., Redmond, WA) and the minimum, 25th percentile, median, 75th percentile, and maximum scores and percentage of producers' answers were calculated using Excel (version 2003 and 2007; Microsoft Corp.).

\section{RESULTS AND DISCUSSION}

Our results are presented and discussed in terms of whether the main goals - the feasibility of using the tool on commercial farms and the likelihood that it would be used by advisors or producers to improve cow comfort on farms - were achieved.

\section{Duration of the Assessment}

The time needed to conduct the assessment is a determining factor to ensure tool practicality. A 3- to 4-h limit was mentioned by extension specialists (equivalent to half a working day for an assessor, excluding traveling time). Two visits within a week of each other, lasting on average 8 and $9 \mathrm{~h}$ (range between freestall and tiestall farms) and 4 and $4.1 \mathrm{~h}$ respectively, were scheduled to complete data collection by 2 assessors for the cow comfort assessment.

The animal-based measures took, on average, 6.5 to $7.5 \mathrm{~h}$ (range between freestall and tiestall farms) when 2 assessors were scoring simultaneously. Environmentbased measures taken in the barn accounted for, on average, $2.1 \mathrm{~h}$ (both for freestall and tiestall farms), and management-based measures taken from the questionnaire accounted for $0.8 \mathrm{~h}$. Other aspects of the visit included preparation work (e.g., finalizing report for producers, disinfecting equipment) and discussion of a farm's scores with the producer. Time involving producers accounted for $1.7 \mathrm{~h}$. Animal-based measures are important in animal welfare assessments because they are considered to be more closely linked to the actual welfare state of animals, as they measure the state of the animal rather than its environment (Whay et al., 2003; Webster et al., 2004). However, the inclusion of animal-based measures in welfare assessment protocols increase the assessment time as well as cost. For example, the Welfare Quality assessment protocol for dairy cattle is very time consuming (about $1 \mathrm{~d}$ per herd) and the animal-based measures take about $90 \%$ of the total assessment time (de Vries et al., 2012). In our assessment tool, the number of animal-based measures (11) was reduced and behavioral measures were not included other than lameness scoring (Gibbons et al., 2014), lying time (Vasseur et al., 2012), and slips and falls (Rushen and de Passillé, 2006) when encouraging cows to walk to the milking parlor (freestall only).

Several strategies can reduce on-farm assessment time while still assessing animal-based measures. First, technology is becoming available that will allow automatic monitoring of measures. Lying time was a key measure in our study but the technology that used was time consuming because the accelerometers must be attached and removed at the milking parlor in both freestall and tiestall farms, taking $2.5 \mathrm{~h}$, on average, on 2 separate occasions. An additional constraint with recording lying time was the time required to download the accelerometer data (2.5 h with both assessors) on farm if the aim is to provide herd lying time to the producers before departure from the farm. However, activity loggers such as accelerometers are now frequently used on commercial farms (e.g., to monitor estrus), and it is likely that in the future lying time could be available directly from farm computers rather than requiring extra equipment and time.

The producers were very interested in the measure of lying time and this measure was used in our assessment tool as a means of interesting them in the project. In our previous on-farm intervention on calf welfare improvement, we demonstrated that introducing producers to new technology is a way to get buy-in from them in the assessment of their farm (Vasseur et al., 2010).

Other limitations in gathering animal-based measures due to the experimental design of the epidemiology study aiming at evaluating risk factors substantially increased the duration of assessment. Indeed, the sampling strategy required targeting a specific group of cows (early lactating cows) and identifying and individualizing data. This sampling strategy would not be necessary when restricting data collection to the sole purpose of an on-farm assessment. 


\section{(a) Free-stall farms}

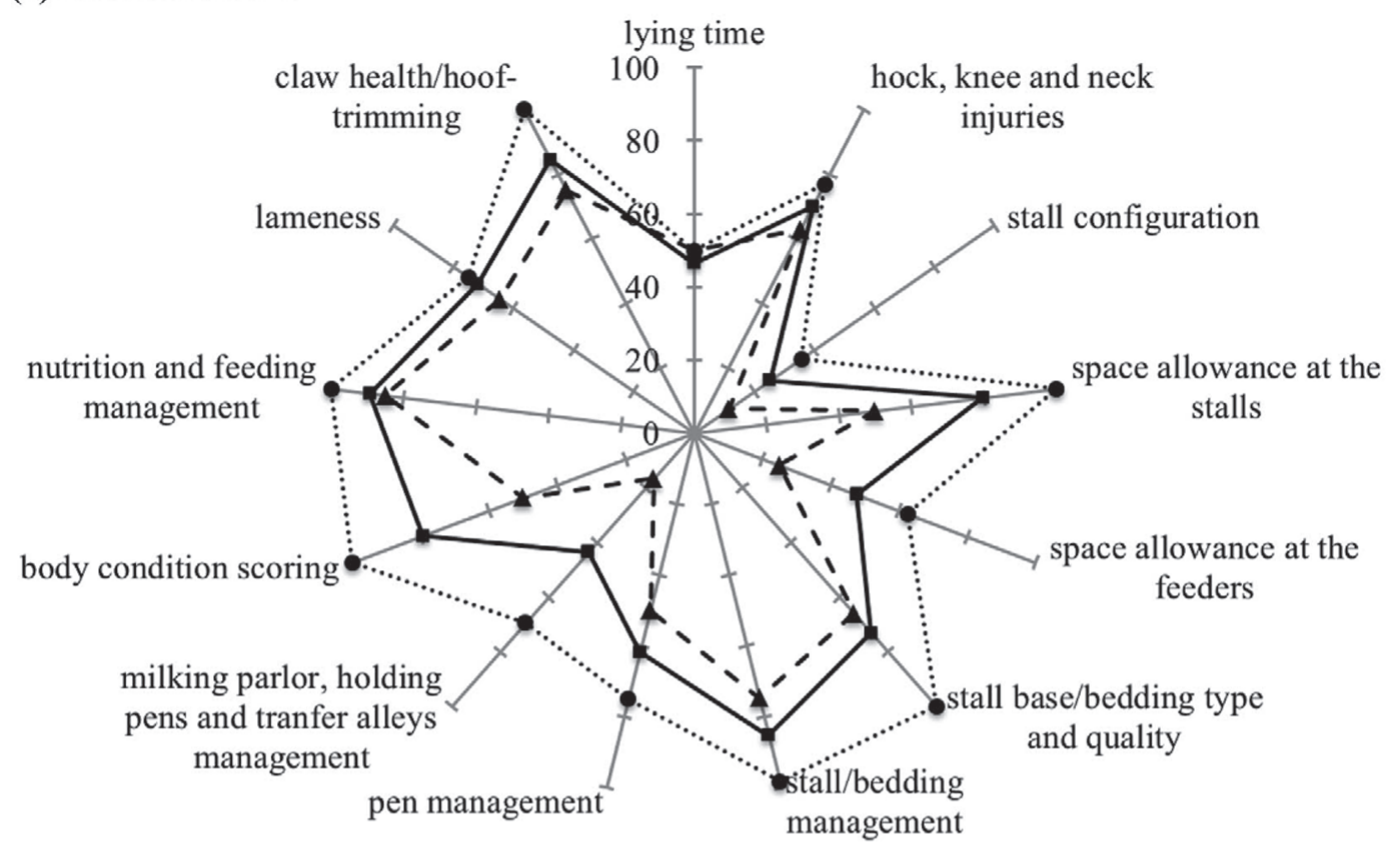

\section{(b) Tie-stall farms}

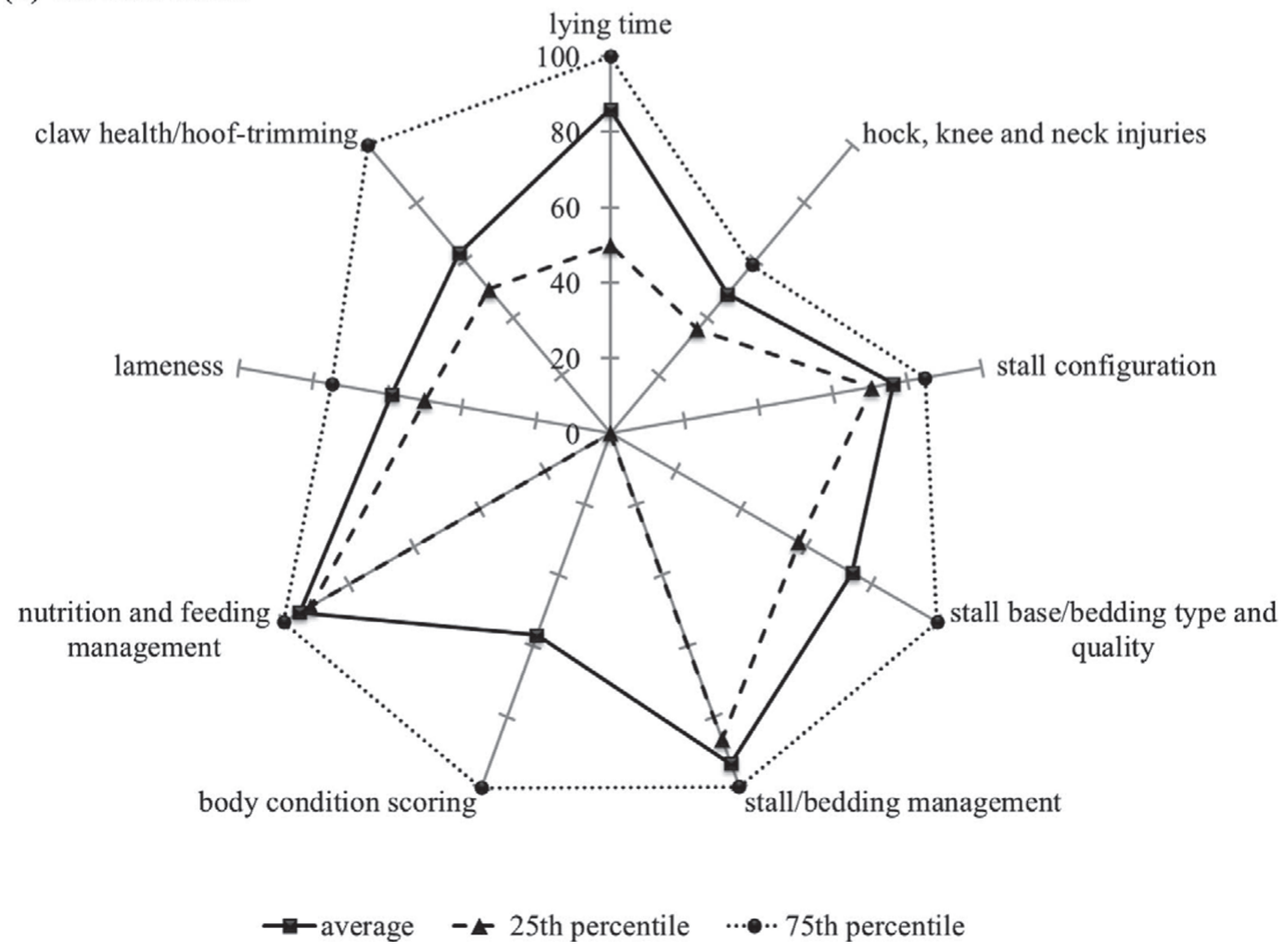

Figure 1. Average, 25th percentile, and 75th percentile scores for critical areas of dairy cow comfort on (a) freestall and (b) tiestall farms.

Another strategy for shortening assessment time is to use farm records to estimate the incidence of measures instead of using estimates of the prevalence at the time of the visit. This strategy requires keeping standardized, validated, and systematically recorded health or performance data at the herd level, which remains a considerable challenge despite the number of software tools available and services offered by DHI 
agencies or veterinarian associations. Some countries have implemented systematic recording for years, relying on their national databases, and are able to draw a first animal welfare assessment remotely (Nyman et al., 2011; Torsein et al., 2014).

\section{Ease of Data Collection and Repeatability of Measures}

No major problems were encountered in collecting the measures. This is likely because all components of our tool had been tested before the study and validated for scientific quality, and the training of assessors was developed with care. Some minor problems encountered were mainly linked to specific farm set-ups (e.g., the layout of some milking parlors did not allow us to score both hocks for injuries), and assessors had to develop creative strategies to complete the assessment (e.g., scoring the remaining hocks in the freestall pens). To further ensure data quality, SOPs were developed so that all assessors judged measures in the same way, and periodic checks were conducted to ensure that repeatability was maintained above target agreement of weighted kappa $\geq 0.6$ during the data collection period for injuries (Gibbons et al., 2011), BCS (Vasseur et al., 2013), lameness (Gibbons et al., 2014), and cleanliness (J. Gibbons, E. Vasseur, J. Rushen, and A. M. de Passillé; unpublished data) as well as all qualitative measures (e.g., quantity of bedding, cleanliness of stalls, management questions). These latter SOPs were all submitted to the same process of development, test, validation, training, and data quality control, following Vasseur et al. (2010).

\section{Having Realistic Targets}

For the tool to be useful, the targets set should be realistic in terms of their ability to discriminate between herds and not be so high as to discourage producers. However, the targets should not be set so low that all producers achieve them easily, even if they have real problems on their farm. Targets would be considered realistic if average farm scores were around $50 \%$ for most of the targets. Freestall and tiestall farm scores are presented separately. These scores need to be considered with caution when comparing farms because scores may not always be calculated the same way between housing systems. Scores need to be considered also in limitations regarding the representativeness of the general population of dairies due to nonrandom selection of herds and cows in herds.

Freestall farms had average scores ranging from 25 to $89 \%$ for all 13 critical areas (Figure 1). For freestall farms, the bottom quartile farms (25th percentile) scored up to $50 \%$ (not included) on 3 of the 13 critical areas, covering stall configuration; space allowance at the feeders; and management of the milking parlor, holding pens, and transfer alleys. A score of $100 \%$ was reached by the top quartile of freestall farms (75th percentile) for 5 of the 13 critical areas, covering space allowance at the stalls; stall base and bedding type and quality; body condition scoring; nutrition and feeding management; and claw health and hoof-trimming. Few freestall farms met the targets regarding stall configuration (Table 1). Based on stall dimensions and cow size on each farm, the percentage of cows that would fit the width and length of the stalls was calculated. We established that, on average, 35\% (range, $0-100 \%$ ) of the cows would fit the average stall for bed length and width, based on DFC Code of Practice (DFC-NFACC, 2009) recommendations. Few freestall farms met the targets regarding space allowance at the feeders (Table 1 ). Based on the width of the alley where cows stand to feed, we established that $80 \%$ of farms did not meet DFC Code of Practice recommendations to allow sufficient space for feeding and animal displacement (4.1 $\mathrm{m}$, allowing 5\% below target). Most freestall farms did not reach the targets regarding management of milking parlor, holding pens, and transfer alleys (Table 1). Based on the type of flooring, 68 to $73 \%$ of farms did not meet DFC Code of Practice recommendations to minimize the time cows spend on concrete in the milking parlor, holding area, and alleys to the milking parlor.

Tiestall farms had average scores between 48 and $95 \%$ for all 9 critical areas (Figure 1). The bottom quartile of tiestall farms (25th percentile) scored up to $50 \%$ (not included) on 2 of the 9 critical areas, covering hock, knee, and neck injuries; and body condition scoring. A score of $100 \%$ was reached for 5 of the 9 critical areas by the top quartile of freestall farms (75th percentile), covering lying time; stall base and bedding type and quality; body condition scoring; nutrition and feeding management; and claw health and hoof trimming. Few tiestall farms met the target regarding hock, knee, and neck injuries (Table 1). Based on the herd prevalence, we established that, on average, $48 \%$ (range, 14-83\%) of cows did not show any injuries for the 3 types of injuries. Few tiestall farms met the target regarding body condition scoring (Table 1). Based on the number of cows with BCS $\leq 2$ (poor BCS) in each herd, it was established that $57 \%$ of farms did not meet DFC Code of Practice recommendations that no cow should be at a BCS of 2 or lower (poor BCS).

Therefore, we concluded that our tool would help producers and advisors identify key areas that affect cow comfort on their farms and help the producers monitor and improve cow comfort and so meet the 
requirements and recommendations of the Code of Practice. Our tool's targets were realistic in terms of its ability to discriminate between herds.

\section{Producer Evaluation of Our Tool}

Producer evaluation of our tool was surveyed because producers are the end users of the tool and the best judges of the usefulness of an assessment tool. Overall, producers agreed that this was a useful tool to assess cow comfort at the farm level (freestall: $86 \%$; tiestall: $95 \%$ ) and agreed that the tool is easy to use on farm (freestall: $61 \%$; tiestall: $82 \%$ ). Most producers agreed that the tool was useful in identifying changes in management practices (freestall: 83\%; tiestall: 93\%) on their farm that would improve cow comfort. However, even if surveyed producers were convinced of the effectiveness of our tool for assessing cow comfort, only half of the producers were in favor of using this tool for a cow comfort accreditation (freestall: $47 \%$; tiestall: $61 \%$ ). This could be viewed in the context of producers' results, which indicated room for improvement in cow management and environment to improve cow comfort on surveyed tiestall and freestall farms. Furthermore, our cow comfort tool assessment was presented as a voluntary tool for producers and their advisors; accreditation involves a compulsory aspect that was not implied at the time of the study.

Concerning the steps of the visits, producers mainly agreed that the questionnaire on management (freestall: 94\%; tiestall: 100\%) and evaluation of conditions in the barn (freestall: 94\%; tiestall: 99\%) took an acceptable amount of time (although the producers were not present for the barn data collection). Most producers perceived the debriefing to be very satisfactory and very important (freestall: 96\%; tiestall: 100\%); indeed, producers liked this period of discussion where they received explanations of the scoring and recommendations.

Finally, $55 \%$ of freestall producers and $58 \%$ of tiestall producers provided one or more suggestions for improving the cow comfort assessment tool. From those respondents, $20 \%$ wanted more recommendations for improvement, even if the farm's individual evaluation was discussed in regards to the Code of Practice (DFCNFACC, 2009). An optimal goal of the tool is to serve as a basis for an advisory service offered by field advisors; therefore, once areas of improvement are targeted, producers and advisors together could develop a plan for improvement. From respondents, 25\% suggested to add measures to the tool mainly on the environment, including (from the most to the least suggested measure): ventilation and air quality, lighting, water flow, and voltage (electric dressers). Those measurements could be added to the tool, along with recommendations.

Following the end of our study, DFC volunteered to develop an animal care assessment program using a framework developed by the National Farm Animal Care Council starting in January 2012. The cow comfort assessment tool described in this paper served as background material for the DFC assessment program (including training process, animal-based measures protocols, results helping the development of target thresholds). The animal care assessment program is now part of "The proAction Initiative: On-Farm Excellence" launched by DFC in July 2013, a coordinated national framework aiming to demonstrate responsible Canadian dairy farmers' stewardship for their animals and the environment, sustainably producing high quality, safe, and nutritious food for consumers.

\section{CONCLUSIONS}

The main goals of developing a successful assessment tool to help producers improve cow comfort and meet the requirements and recommendations of the DFC Code of Practice (DFC-NFACC, 2009) were achieved. The target of a 3-h time limit would be achievable once the tool is being used for farm evaluation rather than part of an experimental study evaluating risk factors. No problems were encountered collecting management-, environment- and animal-based measures, showing that the training program and materials developed for data collection were sufficient. Our tool was effective at identifying both good practices and improvements to implement on farm, and our targets could realistically be reached by producers. The end users of our tool were convinced of the effectiveness of our tool for assessing cow comfort and helping producers make decisions toward improvements. A follow-up study would evaluate how effective our intervention was at initiating changes in cow management and environment to improve cow comfort. Alternatively, one single farm intervention may be not enough to encourage the implementation of all requirements and recommendations of the Code of Practice; therefore, this tool could easily serve as basis for an advisory service offered by field advisors to enhance improvements of cow comfort on freestall and tiestall farms across Canada. The cow comfort assessment tool described in this paper served as background material for the Dairy Farmers of Canada animal care assessment program launched in July 2013.

\section{ACKNOWLEDGMENTS}

This study was funded by Agriculture and AgriFood Canada (AAFC; Ottawa, Ontario, Canada) and 
Dairy Farmers of Canada (Ottawa, Ontario, Canada) as part of the Dairy Science Cluster initiative, the Fonds Québecois de la Recherche sur la Nature et les Technologies (FQRNT; Québec city, Québec, Canada)Novalait (Québec city, Québec, Canada)-Ministère de l'Agriculture, des Pêcheries et de l'Alimentation du Québec (MAPAQ; Québec city, Québec, Canada), and by Alberta Milk (Edmonton, Alberta, Canada). We thank all collaborators and graduate and undergraduate students from University of British Columbia (Vancouver, British Columbia, Canada), University of Calgary (Alberta, Canada), University of Guelph (Ontario, Canada), Université Laval (Québec city, Québec, Canada), Valacta (Sainte-Anne-de-Bellevue, Québec, Canada) and CanWest DHI (Guelph, Ontario, Canada), as well as all dairy producer participants.

\section{REFERENCES}

Bockstaller, C., and P. Girardin. 2003. How to validate environmental indicators. Agric. Syst. 76:639-653.

de Vries, M., B. Engel, I. den Uijl, G. van Schaik, T. Dijkstra, I. de Boer, and E. Bokkers. 2012. Assessment time of the Welfare Quality ${ }^{\circledR}$ protocol for dairy cattle. Anim. Welf. 22:85-93.

DFC-NFACC (Dairy Farmers of Canada and the National Farm Animal Care Council). 2009. Code of Practices for the Care and Handling of Dairy Cattle. Dairy Farmers of Canada, Ottawa, Ontario, Canada.

Gibbons, J., D. B. Haley, J. Higginson Cutler, C. Nash, J. Zaffino Heyerhoff, D. Pellerin, S. Adam, A. Fournier, A. M. de Passillé, J. Rushen, and E. Vasseur. 2014. Technical note: Reliability and validity of a method to measure lameness prevalence of cows in tie-stalls. J. Dairy Sci. 97:350-353.

Gibbons, J., E. Vasseur, J. Rushen, and A. M. de Passillé. 2011. A training programme to ensure high repeatability of injury scoring of dairy cows. Anim. Welf. 21:379-388.

Ingvartsen, K. L., R. J. Dewhurst, and N. C. Friggens. 2003. On the relationship between lactational performance and health: Is it yield or metabolic imbalance that cause production diseases in dairy cattle? A position paper. Livest. Prod. Sci. 83:277-308.

Kielland, C., L. E. Ruud, A. J. Zanella, and O. Østerås. 2009. Prevalence and risk factors for skin lesions on legs of dairy cattle housed in freestalls in Norway. J. Dairy Sci. 92:5487-5496.

Mench, J. A. 2008. Farm animal welfare in the U.S.A.: Farming practices, research, education, regulation, and assurance programs. Appl. Anim. Behav. Sci. 113:298-312.
Nyman, A. K., A. Lindberg, and C. H. Sandgren. 2011. Can precollected register data be used to identify dairy herds with good cattle welfare? Acta Vet. Scand. 53(Suppl. 1):S8.

Rushen, J., A. Butterworth, and J. C. Swanson. 2011. Animal behavior and well-being symposium: Farm animal welfare assurance: Science and application. J. Anim. Sci. 89:1219-1228.

Rushen, J., and A. M. de Passillé. 2006. Effects of roughness and compressibility of flooring on cow locomotion. J. Dairy Sci. 89:29652972.

Rushen, J., D. M. Weary, V. Smid, K. Plaizier, C. Girard, and M. Hall. 2009. Code of Practice for the Care and Handling of Dairy Cattle: Review of Scientific Research on Priority Issues. National Farm Animal Care Council, Canada.

Sørensen, J. T., T. Rousing, S. H. Møller, M. Bonde, and L. Hegelund. 2007. On-farm welfare assessment systems: What are the recording costs? Anim. Welf. 16:237-239.

Torsein, M., M. Jansson-Mörk, A. Lindberg, C. Hallén-Sandgren, and C. Berg. 2014. Associations between calf mortality during days 1 to 90 and herd-level cow and production variables in large Swedish dairy herds. J. Dairy Sci. 97:6613-6621.

Vasseur, E., J. Gibbons, J. Rushen, and A. M. de Passillé. 2013. Development and implementation of a training program to ensure high repeatability of body condition scoring of dairy cows. J. Dairy Sci. 96:4725-4737.

Vasseur, E., J. Rushen, A. M. de Passillé, D. Lefebvre, and D. Pellerin 2010. An advisory tool to improve management practices affecting calf and heifer welfare on dairy farms. J. Dairy Sci. 93:4414-4426.

Vasseur, E., J. Rushen, D. B. Haley, and A. M. de Passillé. 2012. Sampling cows to assess lying time for on-farm animal welfare assessment. J. Dairy Sci. 95:4968-4977.

Webster, A. J. F., D. C. J. Main, and H. R. Whay. 2004. Welfare assessment: Indices from clinical observation. Anim. Welf. 13:S93S98.

Whay, H. R., D. C. J. Main, L. E. Green, and A. J. F. Webster. 2003 Assessment of the welfare of dairy cattle using animal-based measurements: Direct observations and investigation of farm record. Vet. Rec. 153:197-202.

Zaffino Heyerhoff, J. C., S. LeBlanc, T. DeVries, C. Nash, J. Gibbons, K. Orsel, H. Barkema, L. Solano, J. Rushen, A. M. de Passillé, and D. Haley. 2014. Prevalence of, and factors associated with, hock, knee, and neck injuries on dairy cows in free-stall housing in Canada. J. Dairy Sci. 97:173-184.

Zurbrigg, K., D. Kelton, N. Anderson, and S. Millman. 2005a. Stal dimensions and the prevalence of lameness, injury, and cleanliness on 317 tie-stall dairy farms in Ontario. Can. Vet. J. 46:902-909.

Zurbrigg, K., D. Kelton, N. Anderson, and S. Millman. 2005b. Tiestall design and its relationship to lameness, injury, and cleanliness on 317 Ontario dairy farms. J. Dairy Sci. 88:3201-3210. 